\title{
Fine-root traits of allelopathic rice at the seedling stage and their relationship with the allelopathic potential
}

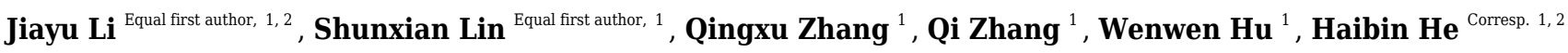 \\ 1 Fujian Provincial Key Laboratory of Agroecological Processing and Safety Monitoring, College of Life Sciences, Fujian Agriculture and Forestry University, \\ Fuzhou, Fujian, China \\ ${ }^{2}$ Key Laboratory of Crop Ecology and Molecular Physiology, Fujian Agriculture and Forestry University, Fuzhou, Fujian, China \\ Corresponding Author: Haibin He \\ Email address: ljy@fafu.edu.cn
}

Background. Allelopathic rice releases allelochemicals through its root systems, thereby exerting a negative effect on paddy weeds. This research aimed to evaluate the relationship between fine-root traits and the rice allelopathic potential at the seedling stage. Methods. Two allelopathic rice cultivars, 'PI312777' and 'Taichung Native1,' and one non-allelopathic rice cultivar, 'Lemont,' were grown to the 3-6 leaf stage in a hydroponic system. Their fine roots were collected for morphological trait (root length, root surface area, root volume, and root tips number) in smaller diameter cutoffs and proliferative trait (root biomass) analysis. Their root-exudates were used for quantitative analysis of phenolic acids contents and an evaluation of allelopathic potential. Correlation analysis was also used to assess whether any linear relationships existed. Results. Our results showed that allelopathic rice cultivars had significantly higher fine-root length having diameters $<0.2 \mathrm{~mm}$, more root tips number, and greater root biomass, coupled with higher allelopathic potential and phenolic acid contents of their root exudates, comparing with non-allelopathic rice cultivar. And these fine-root traits were significantlypositively correlated to allelopathic inhibition and total phenolic contents in rice rootexudates. However, there were not significant correlations among the rice allelopathic potential and total phenolic acid contents of rice root-exudates with the root length, root surface area, and root volume of fine root in diameter $>0.2 \mathrm{~mm}$. Discussion. Our results implied that fine-root traits appears to be important in understanding rice allelopathy at the seedling stage. The high allelopathic potential of rice cultivars might be attributed to their higher length of fine roots $<0.2 \mathrm{~mm}$ in diameter and more number of root tips of fine root, which could accumulate and release more allelochemicals to solutions, thereby resulting in high inhibition on target plants. The mechanisms regulating this process need to be further studied. 
1 Fine-root traits of allelopathic rice at the seedling stage and their relationship with the allelopathic potential

2

3

4

5

6

7

8

9

10

11

12

13

14

15

16
Fujian Agriculture and Forestry University, Fuzhou, China.

2 Key Laboratory of Crop Ecology and Molecular Physiology, Fujian Agriculture and Forestry University, Fuzhou, China

* Correspondence Author: Haibin He, E-mail: ljy@fafu.edu.cn Tel: +86 59183703791. Fax: +86 59183769440

(5) These authors contributed equally to this work. 
18

19

\section{Abstract:}

Background. Allelopathic rice releases allelochemicals through its root systems, thereby exerting a negative effect on paddy weeds. This research aimed to evaluate the relationship between fine-root traits and the rice allelopathic potential at the seedling stage.

Methods. Two allelopathic rice cultivars, 'PI312777' and 'Taichung Native1,' and one non-allelopathic rice cultivar, 'Lemont,' were grown to the 3-6 leaf stage in a hydroponic system. Their fine roots were collected for morphological trait (root length, root surface area, root volume, and root tips number) in smaller diameter cutoffs and proliferative trait (root biomass) analysis. Their root-exudates were used for quantitative analysis of phenolic acids contents and an evaluation of allelopathic potential. Correlation analysis was also used to assess whether any linear relationships existed.

Results. Our results showed that allelopathic rice cultivars had significantly higher fine-root length having diameters $<0.2 \mathrm{~mm}$, more root tips number, and greater root biomass, coupled with higher allelopathic potential and phenolic acid contents of their root exudates, comparing with non-allelopathic rice cultivar. And these fine-root traits were significantly-positively correlated to allelopathic inhibition and total phenolic contents in rice root-exudates. However, there were not significant correlations among the rice allelopathic potential and total phenolic acid contents of rice root-exudates with the root length, root surface area, and root volume of fine root in diameter $>0.2 \mathrm{~mm}$.

Discussion. Our results implied that fine-root traits appears to be important in understanding rice allelopathy at the seedling stage. The high allelopathic potential of rice cultivars might be attributed to their higher length of fine roots $<0.2 \mathrm{~mm}$ in diameter and more number of root tips of fine root, which could accumulate and release more allelochemicals to solutions, thereby resulting in high inhibition on target plants. The mechanisms regulating this process need to be further studied.

\section{Introduction}

Allelopathy is the study of interactions between plants which a donor plant release biochemicals (known as allelochemicals) that influence the germination, growth, survival, and reproduction of a receiver plant (Rice, 1984). Root exudation is one of the major pathways of allelochemicals release into environment, which was one of root exudates (Dilday, Nastasi \& Smith, 1989; Rice, 1984). The view that allelopathy is related to plant root was first reported in the study of walnut tree where no grass would occur underneath a walnut tree, and death line of the tested 
46 plants underneath walnut tree was the same as the growth line of black walnut root (Rietveld, 1983). Juglone was

47 primarily produced by these living walnut roots and was detected in the rhizosphere soil surrounding the living roots

48 (Jose \& Gillespie, 1998). Recently, there is no doubt that plant roots and root exudates are the key factors in 49 belowground plant-plant interactions (Bertin et al., 2003; Bais et al., 2004; Baetz \& Martinoia 2014; Tsunoda \& Dam 50 2017).

51 The accumulation of root exudates in specialized organs in living roots and their potential role in plant-plant interactions have been documented for several crop and medicinal species. In 2001, Czarnota et al. (2001) described localization and release of sorgoleone by living sorghum root hairs as plant growth inhibitors. Some flavonoids have been shown to mediate allelopathic interactions in the plant rhizosphere, which can accumulate at the root tip of white clover and in root cap cells from where they can be exuded into the soil (Weston \& Mathesius, 2013).Through confocal and light microscopic imaging techniques, Zhu et al. (2016) revealed that bioactive naphthoquinones were released by direct exudation in droplets which accumulated at the tips of living root hairs in E. plantagineum. However, there are relatively few studies that have focused on location and release of allelochemicals from plant roots into the rhizosphere of allelopathic rice. Rice allelopathy is first reported in 1990s when Dilday and his colleges found some rice have apparent inhibition effect on neighbouring paddy weeds in field test (Dilday, Nastasi \& Smith, 1989). They observed that allelopathic rice PI312777 and PI338046 had the greatest root biomass whereas non-allelopathic rice Lemont and M-201 had the least root biomass (Dilday, Mattice, \& Moldenhauer, 2000). Gealy, Moldenhauer \& Duke (2013) quantified the root distribution and potential interactions between allelopathic rice and major weeds using stable ${ }^{13} \mathrm{C}$ isotope discrimination analysis, and the results demonstrated that under weed-free conditions, the roots of the allelopathic cultivars explore the upper soil profile more thoroughly than non-allelopathic cultivars. Thus, we hypothesized there were important relationships between root traits (root tips and root biomass) and rice allelopathy.

Generally, plant root includes meristermatic zone where cell division take place, elongation zone where cells expand along the longitudinal axis, and the differentiation zone where root hairs develop. The root elongation grows by root tip growth that restricted to the growing apex (Datta et al., 2011). Root diameter has a strong influence on root trait variation across plant species, growth forms and biomes (Ma et al., 2018). Fine roots, traditionally defined as all roots $\leq 2 \mathrm{~mm}$ in diameter, are primary acquisition organs and mediate biochemical process in terrestrial ecosystems (McCormack et al., 2015). More recently, some studies have assigned increasingly smaller diameter cutoffs (e.g. 1.0 
whether there was a possibility that rice allelopathy was related to root fineness.

To test our hypothesis and clarify the above question, we explored the differential of root traits between allelopathic and non-allelopathic rice at the seedling stages, determined the contents of phenolic acids and allelopathic potential of rice root-exudates, and further analyzed their correlation. Investigating the morphological and proliferative traits of allelopathic rice fine-roots at the seedling stages could help us to understand the formation mechanism of the weed-suppressing zone, and then to extend the weed control area by modifying rice root system.

\section{Materials \& Methods}

\section{Plant Growth, Sampling, and Root Trait Calculation}

Two internationally recognized allelopathic rice cultivars, 'PI312777' (PI) and 'Taichung Native1' (TN), and one non-allelopathic rice cultivar, 'Lemont' (Le) (Dilday, Mattice, \& Moldenhauer, 2000), were used in this study. The experiments were conducted in a completely randomized design with three replicates for each cultivar. Surfacesterilized seeds were pregerminated in Petri dishes. Ten uniform seedlings at 1-leaf stage were inserted into the holes of a polystyrene float $(27 \mathrm{~cm} \times 17 \mathrm{~cm} \times 1.5 \mathrm{~cm})$, which was floated in a plastic pot $(29 \mathrm{~cm} \times 19 \mathrm{~cm} \times 15 \mathrm{~cm}) \mathrm{containing}$ 5 L of Hoagland's nutrient solution. Additional distilled water was added to each pot daily to maintain the same volume, and Hoagland's solution was added to each pot every $7 \mathrm{~d}$. When the rice seedlings were at the 3-, 4-, 5-, and 6-leaf stage, the seedlings were harvested, and their roots were collected for analysis of morphological and proliferation traits.

The fine-root traits were analyzed according to the procedure of Lupini et al. (2016) and Zhang, Fan \&Wang (2018). Briefly, three plants of each rice cultivar were randomly selected for root analysis. The clean and intact roots were scanned with an Epson Expression 11000XL scanner (Seiko Epson Co., Nagano-ken, Japan) to yield a grayscale image. The image was processed with WinRHIZO (Regent Instruments Inc., Quebec, Canada) to obtain the following morphological traits: root length, root surface area, root volume in smaller diameter cutoffs $(0.06,0.08,0.10,0.2,0.5$, 1.0 , and $2.0 \mathrm{~mm}$ ) of fine root, and root tips number, which were analyzed by WinRHIZO software. And then the roots were oven-dried at $105^{\circ} \mathrm{C}$ for $30 \mathrm{~min}$ and $80^{\circ} \mathrm{C}$ for $48 \mathrm{~h}$ to obtain the root biomass.

The rice culture solutions were collected and filtered through Whatman No. 1 filter paper. The filtrate was concentrated to $<200 \mathrm{~mL}$ by rotary evaporation at $40^{\circ} \mathrm{C} \pm 1^{\circ} \mathrm{C}$, then stored at $4{ }^{\circ} \mathrm{C}$ in a refrigerator for $24 \mathrm{~h}$. In this process, the inorganic salts were precipitated and removed by filtration. The filtrate was filtered through a $0.22-\mu \mathrm{m}$ membrane and diluted to a volume of $200 \mathrm{~mL}$. This solution was used as the concentrated root-exudates for evaluation 
102 of the allelopathic potential and quantitative analysis of phenolic acids (Li et al., 2017; Zhang et al., 2018).

103 Evaluation of allelopathic potential of rice cultivars

104 The allelopathic potential of the rice cultivars was evaluated using the concentrated root exudates in laboratory 105 bioassay, as described by Zhang et al. (2018). Five milliliters of the concentrated root exudates above at each leafstage was added to tissue culture flasks lined with a filter paper at the base, with Hoagland's solution as a control. Five germinating lettuce (Lactuca sativa L.) seeds were sown on the filter paper of the tissue culture flask that was placed in an incubator $\left(25 \pm 2^{\circ} \mathrm{C}, 12\right.$-h light, 6:00-18:00). All of the experiments were repeated three times, and the root length of lettuce was measured after $3 \mathrm{~d}$, and then the plant was oven dried at $105^{\circ} \mathrm{C}$ for 30 min and $80^{\circ} \mathrm{C}$ for 48

$\mathrm{h}$ to obtain the plant dry weight. The $\%$ inhibition was used to assess allelopathic potential of three rice cultivars, and was calculated as follows: \% inhibition $=(1-\mathrm{T} / \mathrm{C}) \times 100 \%$, based on the root length and plant dry weight of barnyard grass in treatments $(T)$ and in controls $(C)$.

\section{Quantification of phenolic acids in the rice root-exudates}

The contents of single phenolic acids in the rice root-exudates were quantified using the external standard method by solid-phase extraction-high-performance liquid chromatography (SPE-HPLC) as described previously (Li et al., 2017). The concentrated root-exudates at each leaf-stage were loaded onto Cleanert PEP solid phase extraction cartridges (Agela, China). The cartridge was eluted with water and then methanol, and the methanol fraction was concentrated with $\mathrm{N}_{2}$, which was resolved by methanol to $500 \mu \mathrm{L}$ for quantitative analysis using HPLC.

Quantitative analysis was carried out with an HPLC instrument (HPLC-1260, Agilent, USA) equipped with a $\mathrm{C}_{18}$ reverse-phase column (ZORBAX SB-C18, $150 \mathrm{~mm} \times 4.6 \mathrm{~mm}, 5 \mu \mathrm{m})$ with a UV detector, and phenolic acids were detected at $280 \mathrm{~nm}$. The injection volume of the samples was $5 \mu \mathrm{L}$. Elution was performed at a constant flow of 1.6

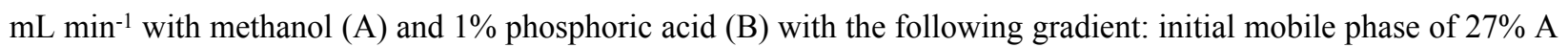
at $9 \mathrm{~min}$, then to $30 \%$ over $2 \mathrm{~min}$, thereafter increased to $50 \%$ for $4 \mathrm{~min}$. The total run time was $15 \mathrm{~min}$. Eight phenolic acids (protocatechuic, $p$-hydroxybenzoic, vanillic, syringic, $p$-coumaric, ferulic, salicylic, and cinnamic acid), that widely recognized as rice allelochemicals (Mattice et al., 1998; Seal, Haig \& Pratley, 2004; He et al., 2012; Li et al., 2017), were chosen as standards for the calibration curve. The concentrations of single phenolic acids in each rice root-exudates were quantified by interpolating the peak area on the HPLC chromatogram to a standard curve constructed from the peak area of the authentic phenolic acids. The phenolic contents were represented as ng per plant.

\section{Statistical analysis}


Data were presented as means \pm standard error (SE) from three replicates for each experiment or determination. In order to determine any significant differences among treatments, data were analyzed using a two-way analysis of variance (ANOVA) with General Linear Model, followed by Tukey’s honestly significant difference (HSD) tests were performed at $P<0.05$. To fulfill the assumptions of the ANOVA, transformations were made when required. Pearson's correlation coefficients $(r)$ between the root morphological traits, root biomass, total phenolic acid contents, and allelopathic potential (\% inhibition on plant dry weight of lettuce) were calculated for three rice cultivars at 3-6 leaf stages $(\mathrm{n}=12)$. All of the data analyses were performed with SPSS 20.0 (SPSS Inc., Chicago, IL, USA).

\section{Results}

\section{Fine-root traits of allelopathic and non-allelopathic rice cultivars}

By the scanning graph, the difference of root growth between three rice cultivars could be obviously observed with the naked eye, including the daughter roots and the adventitious roots. The fine-root traits of allelopathic and nonallelopathic rice cultivars varied in different diameter cutoffs. The results showed that $60-65 \%$ of the total fine-root length sampled of allelopathic rice PI and TN can be accounted for by roots that are $<0.2 \mathrm{~mm}$ in diameter, which was much thinner than that of non-allelopathic rice Le, with $55-60 \%$ of total root length having diameters $>0.2 \mathrm{~mm}$ at $3-6$ leaf stages. In order to make the data easy for statistical analysis, we choose to analyze the differences of fine-root morphology traits of three rice cultivars in three diameter ranges of $0-0.2 \mathrm{~mm}, 0.2-1.0 \mathrm{~mm}$ and $1.0-2.0 \mathrm{~mm}$. As shown in Fig. 1, the total value of fine-root length in diameter $<0.2 \mathrm{~mm}$ were all significant higher in allelopathic cultivars PI and TN than that in non-allelopathic cultivar Le at the same stage. Similarly, root tips number and root biomass were significant higher in PI and TN than that in Le at the same stage (Fig. 2), except not significant difference between $\mathrm{TN}$ and Le at the 3- and the 6-stage. However, the total value of fine-root length that are $<2$ mm in diameter were not significantly different between three rice cultivars at the same stage, and the total value of root surface area and root volume were significant higher in Le than that in PI and TN (Fig. 1).

\section{Fig. 1 and 2near here}

For a given rice cultivars, all morphological traits of fine root increased with leaf stages (Fig. 1 and 2) and these increases were highly significant, as were root biomass traits (Table 1). At seedling stage, the main effect of rice cultivars on fine-root length, root tips number and root biomass was significant (Table 1). Comparing with other fineroot morphological traits, the effect of rice cultivars on the fine-root length less than $0.2 \mathrm{~mm}$ in diameter was more significant. But rice cultivars had little effect on root surface area and root volume. 
159

\section{Allelopathic potential of allelopathic and non-allelopathic rice}

In laboratory bioassay, allelopathic potential of rice root-exudates was expressed by $\%$ inhibition on root length and plant dry weight of lettuce. As shown in Table 1, leaf stages significantly affected allelopathic potential of root exudates, and the \% inhibition was increased with the increase of leaf stages (Fig. 3). At seedling stage, the main effect of rice cultivars on allelopathic potential of rice root-exudates was highly significant (Table 1). Results in laboratory bioassay demonstrated that the root exudates of PI and TN expressed significantly higher inhibition on root length and plant dry weight of lettuce than that of Le at all of 3-6 leaf stages (Fig. 3). The highest of \% inhibition was at 6-leaf stage, showing $56.30 \%$ in PI and $54.25 \%$ in TN on root length of lettuce, respectively, and $32.95 \%$ in PI and $27.27 \%$ in TN on plant dry weight of lettuce, respectively (Fig. 3).

Fig. 3 near here

\section{Phenolic acid contents in the root exudates of allelopathic and non-allelopathic rice}

The contents of eight putative phenolic aicds were detected by SPE-HPLC method. The results showed that variation of each phenolic acid in three rice cultivars was inconsistent as the increase of leaf stages (Table 2). The sum of contents of these eight phenolic acids in root exudates was expressed as total phenolic acids contents in root exudates of three rice cultivars. The main effect of leaf stages and rice cultivars on total phenolic acids contents of rice root exudates was both significant (Table 1). As shown in Fig. 4, total phenolic acids contents were increased with increasing leaf stages, and were significantly higher in PI and TN than that in Le at all of 3-6 leaf stages. Specially, the total contents of the eight phenolic acids reached the maximum at the 6-leaf stage, were $2.36 \mu \mathrm{g}$ plant ${ }^{-1}$ in PI and $1.92 \mu$ g plant $^{-1}$ in TN, as well as in $1.16 \mu \mathrm{g}_{\text {plant }}{ }^{-1} \mathrm{Le}$. It is noteworthy that the contents of cinnamic acid in PI and TN were 8-times and 6-times higher than that in Le, respectively (Table 2).

\section{Table 2 and Fig. 4 near here}

\section{Correlation between root traits and allelopathic potential}

As shown in Table 3, allelopathic potential was significantly correlated with the total phenolic acid contents of rice root-exudates $(r=0.914, \mathrm{P}<0.001)$, fine-root length at $0-0.2 \mathrm{~mm}(\mathrm{r}=0.906, \mathrm{P}<0.001)$, root tips number $(\mathrm{r}=0.921, \mathrm{P}=$ $0.001)$, and root biomass $(\mathrm{r}=0.843, \mathrm{P}=0.001)$, but was not significantly correlated with fine-root length at $0.2-2.0 \mathrm{~mm}$, root surface area, and root volume. The total phenolic acids contents of rice root-exudates was significantly correlated with fine-root length at $0-0.2 \mathrm{~mm}(\mathrm{r}=0.958, \mathrm{P}<0.001)$, root tips number $(\mathrm{r}=0.937, \mathrm{P}<0.001)$, and root biomass 
$186(\mathrm{r}=0.895, \mathrm{P}<0.001)$, but was not significantly correlated with fine-root length at 0.2-2.0 mm, root surface area, and

187 root volume. Besides, the fine-root length at $0-0.2 \mathrm{~mm}$ was significantly correlated with root tips number $(\mathrm{r}=0.972$,

$188 \mathrm{P}<0.001)$ and root biomass $(\mathrm{r}=0.946, \mathrm{P}<0.001)$, and root tips number was significantly correlated with root biomass

$189(\mathrm{r}=0.928, \mathrm{P}<0.001)$. In summary, there were significant correlations among rice allelopathic potential and total

190 phenolic acid contents of rice root-exudates with fine- root length at 0-0.2 mm, root tips number, and root biomass.

\section{Discussion}

192 Plant roots play important roles in belowground interactions with neighboring plants for space, water, and nutrients,

193

194 and with soil microbes (Bais et al., 2004; Callaway \& Mahall 2007; Mallik, Biswas \& Collier, 2016; Laliberté, 2017). On one hand, root traits, including morphology, distribution, architecture, and biotic community influence plant growth, function and biochemical processes (Bardgett, Mommer \& De Vries, 2014; Laliberté, 2017). On the other hand, plant root can synthesize, accumulate, and secrete a diverse array of compounds, referred to as root exudates that impact the soil microbial community, change the physio-chemical properties of soil, and inhibit the growth of competing plant species (Bertin et al., 2003; Bais et al., 2004; Baetz \& Martinoia 2014; Tsunoda \& Dam 2017; Rovira 1969; Walker et al., 2003).

Our hypothesis was there were important relationships between root traits (root tips and root biomass) and rice allelopathy. This proved to be true for allelopathic rice regardless of leaf stages. Our results clearly showed that two allelopathic rice cultivars PI and TN had significantly higher more root tips number, and greater root biomass, coupled with higher allelopathic inhibition and phenolic contents of their root-exudates, comparing with non-allelopathic rice Le at the allelopathic stage (i.e. at 3-6 leaf stages) in a hydroponic system. (Figs. 1-4). All results were in agreement with most previously reported results. Dilday, Mattice \& Moldenhauerfirst (2000) previously reported that allelopathic rice cultivars had the greatest root biomass than non-allelopathic rice cultivars in field test. Until recently, Gealy et al. also observed that the root distribution of allelopathic rice cultivars is shifted towards the upper soil with relatively greater root biomass in comparison to non-allelopathic rice cultivars (Gealy \& Moldenhauer, 2012; Gealy, Moldenhauer \& Duke, 2013). In addition, these root traits were significantly-positively correlated to allelopathic inhibition and total phenolic contents in rice root-exudates (Table 3), which has not been reported before. It seems that more root tips and root biomass might help the exudation accumulation in root tips, and is similar to that observed in living E. plantagineum roots (Zhu et al., 2016). However, we need to further explore the mechanism of localization and release of allelochemicals from rice roots into the rhizosphere. 
214

215

216

217

218

219

220

221

222

223

224

225

226

227

228

229

230

231

232

233

234

235

236

237

238

239

240

241

The root system of a rice plant consists of seminal root originated from the seed and adventitious roots formed from the stem. Formation, emergence, elongation and branching of adventitious roots proceed along the main stem, to keep pace with successive leaf stage (Morita \& Abe, 1993). As observed in fine roots of nine American trees by Pregitzer et al. (2002), roots $<0.2 \mathrm{~mm}$ in diameter would account for the majority of the fine roots in two allelopathic rice cultivars regardless of leaf stages. Moreover, fine-root length $<0.2 \mathrm{~mm}$ in diameter were all significantly higher in allelopathic cultivars PI and TN than that in non-allelopathic cultivar Le at the same stage (Fig. 1). Furthermore, there were significant correlations among the rice allelopathic potential and total phenolic acid contents of rice rootexudates with fine-root length at 0-0.2 $\mathrm{mm}$ in diameter. However, there were not significant correlation relationships among the rice allelopathic potential and total phenolic acid contents of rice root exudates with the length of fine root $>0.2 \mathrm{~mm}$ in diameter, root surface area, and root volume (Table 3). All this indicates that the most reasonable fine root size class for allelopathic rice we studied would consist of all roots smaller size in diameter than non-allelopathic rice. Moreover, the longer the length of fine roots less than $0.2 \mathrm{~mm}$ in diameter, the more likely allelochemicals are to be released and diffused into the soil, which needs to be further explored.

Rice allelopathy involved in the chemical-mediated interaction between rice and neighbouring weeds (He et al., 2012; Kato-Noguchi \& Ino, 2013; Zhang et al., 2018). Allelopathic rice expressed suppressive- activity on weeds when the plant from the 3- to 7-leaf stages and reached the maximum at 5-6 leaf stages (Li et al., 2015). Large quantities of root exudates, including phenolic acids, were typically released from living root hairs (Baetz \& Martinoia, 2014; Bertin, Yang \& Weston, 2003; Lynch, 1995). In this paper, we once again proved that there were significant differences in contents of phenolic acid in root exudates between allelopathic and non-allelopathic rice at seedling stage, which was consistent with previous report ( $\mathrm{Li}$ et al., 2017). Above all, the differences were significantly correlated with fine-root traits and allelopathic potential of rice roots. These results implied that there was a close linkages between the structural attributes of fine roots and how they control the weed. The high allelopathic potential of rice cultivars might be attributed to their higher length of fine roots $<0.2 \mathrm{~mm}$ in diameter and more number of root tips of fine root, which could accumulate and release more allelochemicals to solutions, thereby resulting in high inhibition on target plants. However, the mechanisms regulating this process need to be further studied.

A lot of researches confirmed that modifying crop root systems could increase crop yield, absorb and utilize of soil nutrients, regulate water under drought or waterlogging stresses, as well as recognize the neighbour plants (Asaduzzamana et al., 2016; Asch et al., 2005; DuPont et al., 2014; Jeong et al., 2013; Jitsuyama, 2015; Uga et al., 
242 2013; Zhang et al., 2009). By genetic approach, Uga et al. (2013) successful altered the growth angle of rice roots in

243 a more downward direction and increased deep rooting, which enabled rice to avoid drought and maintained high

244 yield under drought conditions. Similarly, our results open a novel way for modifying the distribution and architecture

245 of rice root system to enhance rice allelopathy, which needs to be further studied under field conditions.

\section{Conclusions}

247 In this study we found that allelopathic rice cultivars had significantly greater length of fine roots $<0.2 \mathrm{~mm}$ in

248 diameter, more root tips number and greater root biomass of fine root, comparing with non-allelopathic rice cultivar

249 at 3-6 leaf stages in a hydroponic system. These fine-traits were highly correlated with allelopathic potential and the

250 phenolic acid content in rice root-exudates. These findings provide new evidence that rice allelopathy can be enhanced

251 by altering rice root system, and would be useful for weed control in rice field.

252 Acknowledgments

253 We acknowledge Professor Xinyu Zheng and Dr. Jiebo Chen for their helpful suggestions.

\section{References}

255 1. Asaduzzamana M, An M, Pratley JE, Luckett DJ, Lemerle D, Coombes N. 2016.The seedling root response of annual ryegrass (Lolium rigidum) to neighbouring seedlings of a highly-allelopathic canola (Brassica napus).

3. Baetz U, Martinoia E. 2014. Root exudates: the hidden part of plant defense. Trends in Plant Science 19:90-98.

4. Bais HP, Park SW, Weir TL, Callaway RM, Vivanco JM. 2004. How plants communicate using the underground information superhighway. Trends in Plant Science 9: 26-32.

5. Bertin C, Yang XH, Weston LA. 2003. The role of root exudates and allelochemicals in the rhizosphere. Plant and Soil 256: 67-83.

6. Callaway RM, Mahall BE.2007. Plant ecology: family roots. Nature 448: 145-147.

7. Czarnota MA, Paul RN, Dayan FE, Nimbal CI, Weston LA. 2001. Mode of action, localization of production, chemical nature and activity of sorgoleone; a potent PSII inhibitor in Sorghum spp. root exudates. Weed Technology $15,813-825$.

8. Datta S, Kim CM, Pernas M, Pires ND, Proust H, Tam T, Vijayakumar P, Dolan L. 2011. Root hairs: 
270

271

development, growth and evolution at the plant-soil interface. Plant and Soil 346: 1-14.

9. Dilday RH, Mattice JD, Moldenhauer KA. 2000. An overview of rice allelopathy in the USA. In: Kim KU, Shin DH (eds). Rice Allelopathy. pp 15-26.

10. Dilday RH, Nastasi P, Smith JR. 1989. Allelopathic observations in rice (Oryza sativa L.) to ducksalad [Heteranthera limosa (Sw.) Willd]. Journal of Proceedings Arkansas Academy of Science, 43:21-22.

11. DuPont ST, Beniston J, Glover JD, Hodson A, Culman SW, Lal R, Ferris H. 2014. Root traits and soil properties in harvested perennial grassland, annual wheat, and never-tilled annual wheat. Plant and Soil 2: 405-420.

12. Gealy DR, Moldenhauer KAK. 2012. Use of ${ }^{13} \mathrm{C}$ isotope discrimination analysis to quantify distribution of barnyardgrass and rice roots in a four-year study of weed-suppressive rice. Weed Science 60:133-142.

13. Gealy DR, Moldenhauer KAK, Duke S. 2013. Root distribution and potential interactions between allelopathic Rice, Sprangletop (Leptochloa spp.), and barnyardgrass (Echinochloa crus-galli) based on ${ }^{13} \mathrm{C}$ isotope discrimination analysis. Journal of Chemical Ecology 39:186-203.

14. He HB, Wang HB, Fang CX, Wu HW, Guo XK, Liu CH, Lin ZH, Lin WX. 2012. Barnyard grass stress up regulates the biosynthesis of phenolic compounds in allelopathic rice. Journal of Plant Physiology 169: 17471753.

15. Iversen CM, McCormack ML, Powell AS, Blackwood CB, Freschet GT, Kattge J, Roumet C, Stover DB, Soudzilovskaia NA, Valverde - Barrantes OJ, Bodegom PM, Violle C. 2017. A global Fine-Root Ecology Database to address below-ground challenges in plant ecology. New Phytologist 215: 15-26.

16. Jeong JS, Kim YS, Redillas MCFR, Jang G, Jung H, Bang SW, Choi YD, Ha SH, Reuzeau C, Kim JK. 2013. OSNAC5 overexpression enlarges root diameter in rice plants leading to enhanced drought tolerance and increased grain yield in the field. Plant Biotechnology Journal 11:101-114.

17. Jose S, Gillespie AR. 1998. Allelopathy in black walnut (Juglans nigra L.) alley cropping. I. Spatio-temporal variation in soil juglonde in a black walnut-corn (Zea mays L.) alley cropping system in the midwestern USA. Plant and Soil 203: 191-197.

18. Jitsuyama Y. 2015. Morphological root responses of soybean to rhizosphere hypoxia reflect waterlogging tolerance. Canadian Journal of Plant Science 95: 999-1005.

19. Kato-Noguchi H, Ino T. 2013. The chemical-mediated allelopathic interaction between rice and barnyardgrass. Plant and Soil 370:267-275. 
20. Laliberté E. 2017. Below-ground frontiers in trait-based plant ecology. New Phytologist 213: 1597-1603.

21. Li JY, Guo XK, Zhang Q, Liu CH, Lin ZH, Yu ZM, Wu HW, He HB. 2015. A novel screening method for rice allelopathic potential: the inhibitory-circle method. Weed Research 55:441-448.

22. Li JY, Zhang Q, Yang XY, Hu WW, Lin RL, He HB. 2017. A reappraisal of the content and the differences of phenolic acids between allelopathic and non-allelopathic rice accessions. Allelopathy Journal 40: 35-46.

23. Lupini A, SorgonàA, Princi MP, Sunseri F, Abenavoli MR. 2016. Morphological and physiological effects of trans-cinnamic acid and its hydroxylated derivatives on maize root types. Plant Growth Regulation 78:263-273.

24. Lynch J. 1995. Root Architecture and Plant Productivity. Plant Physiology 109: 7-13.

25. Ma ZQ, Guo DL, Xu XL, Lu MZ, Bardgett RD, Eissenstat DM, McCormack ML, Hedin LO. 2018. Evolutionary history resolves global organization of root functional traits. Nature 555: 94-97.

26. Mallik AU, Biswas SR, Collier LCS. 2016. Belowground interactions between Kalmia angustifolia and Picea mariana: roles of competition, root exudates and ectomycorrhizal association. Plant and Soil 403:471-483.

27. Mattice J, Lavy T, Skulman B, Dilday RH. 1998. Searching for allelochemicals in rice that control ducksalad. In: Olofsdotter M (ed) Allelopathy in rice. International Rice Research Institute, Manila, pp 81-98.

28. McCormack ML, Dickie IA, Eissenstat DM, Fahey TJ, Fernandez CW, Guo D, Helmisaari HS, Hobbie EA, Iversen CM, Jackson RB, Leppälammi - Kujansuu J, Norby RJ, Phillips RP, Pregitzer KS , Pritchard SG, Rewald B, Zadworny M. 2015. Redefining fine roots improves understanding of below-ground contributions to terrestrial biosphere processes. New Phytologist 207: 505-518.

29. Morita S, Abe J. 1993. Modeling root system morphology in rice. In: Biology of adventitious root formation. Edited by Tim D. Davis and Bruce E. Haissig. Proceedings of the First International Symposium on the Biology of adventitious root formation. pp 191-202.

30. Pregitzer KS, DeForest JL, Burton AJ, Allen MF, Ruess RW, Hendrick RL. 2002. Fine root architecture of nine North American trees. Ecological Monographs 72: 293-309.

31. Rietveld WJ. 1983. Allelopathic effects of juglone on germination and growth of several herbaceaous and woody species. Journal of Chemical Ecology 9:295-308.

32. Rice EL. 1984. Allelopathy. Orlando: Academic Press. 422.

33. Rovira AD. 1969. Plant root exudates. The Botanical Review 35: 35-57.

34. Seal AN, Haig T, Pratley JE. 2004. Evaluation of putative allelochemicals in rice root exudates for their role in 
326

327

328

329

330

331

332

333

334

335

336

337

338

339

340

341

342

343

344

345

346

the suppression of arrowhead root growth. Journal of Chemical Ecology 30:1663-1678.

35. Tsunoda T, Dam NM. 2017. Root chemical traits and their roles in belowground biotic interactions. Pedobiologia 65: 58-67.

36. Uga Y, Sugimoto K, Ogawa S, Rane J, Ishitani M, Hara N, Kitomi Y, Inukai Y, Ono K, Kanno N , Inoue H, Takehisa H, Motoyama R, Nagamura Y, Wu J, Matsumoto T, Takai T, Okuno K, Yano M. 2013. Control of root system architecture by DEEPER ROOTING 1 increases rice yield under drought conditions. Nature Genetics 45:1097-1102.

37. Walker TS, Bais HP, Grotewold E, Vivanco JM. 2003. Root exudation and rhizosphere biology. Plant Physiology $132: 44-51$.

38. Weston LA, Mathesius U. 2013. Flavonoids: their structure, biosynthesis and role in the rhizosphere, including allelopathy. Journal of Chemical Ecology 39: 283-297.

39. Zhang H, Xue Y, Wang Z, Yang JC, Zhang JH. 2009. Morphological and physiological traits of roots and their relationships with shoot growth in "super" rice. Field Crops Research 13: 31-40.

40. Zhang TS, Fan B, Wang P. 2018. Barnyardgrass root recognition behaviour for rice allelopathy. Agronomy Journal. DOI:10.3390/agronomy8040039

41. Zhang Q, Li L, Li JY, Wang HB, Fang CX, Yang XY, He HB. 2018. Increasing rice allelopathy by induction of barnyard grass (Echinochloa crus-galli) root exudates. Journal of Plant Growth Regulation 37:745-754.

42. Zhu XC, Skoneczny D, Weidenhamer JD, Mwendwa JM, Weston PA, Gurr GM, Callaway RM, Weston LA. 2016. Identification and localization of bioactive naphthoquinones in the roots and rhizosphere of Paterson's curse (Echium plantagineum), a noxious invader. Journal of Experimental Botany, doi:10.1093/jxb/erw182. 


\section{Figure Captions}

349 Fig.1 Total value of root length (A), root surface area (B), and root volume (C) in the fine-root diameter range of 0$350 \quad 0.2,0.2-1.0$ and 1.0-2.0 mm of three rice cultivars (PI and TN, allelopathic cultivars PI312777 and Taichung Native1.

351 Le, non-allelopathic cultivar Lemont) at 3-6 leaf stages. Significant differences $(\mathrm{P}<0.05)$ between rice cultivars at the 352 same leaf stage were indicated by different lowercases, and the significant differences for total values of 0-2.0 mm 353 diameter were indicated by different uppercases at the end of the bars, according to Tukey's honestly test.

Fig.2 Root tip number (A) and root biomass (B) of three rice cultivars (PI and TN, allelopathic cultivars PI312777 and Taichung Native1. Le, non-allelopathic cultivar Lemont) at 3-6 leaf stages. Significant differences $(\mathrm{P}<0.05)$ between rice cultivars at the same leaf stage were indicated by different lowercases, according to Tukey’s honestly test.

Fig.3 The \% inhibition of the root exudates of three rice cultivars (PI and TN, allelopathic cultivars PI312777 and Taichung Native1. Le, non-allelopathic cultivar Lemont) at 3-6 leaf stages. Significant differences $(\mathrm{P}<0.05)$ between rice cultivars at the same leaf stage were indicated by different lowercases, according to Tukey's honestly test.

Fig.4 The total contents of eight phenolic acids in rice root-exudates at 3-6-leaf stage. Significant differences $(\mathrm{P}<0.05)$ between rice species at the same leaf stage were indicated by different lowercases according to Tukey's honestly test. 


\section{Figure 1}

Fig. 1 Total value of root length $(A)$, root surface area $(B)$, and root volume $(C)$ in the fine-root diameter range of $0-0.2,0.2-1.0$ and $1.0-2.0 \mathrm{~mm}$ of three rice cultivars (PI and TN, allelopathic cultivars PI312777 and Taichung Native1. Le, non-allelopathi

Significant differences $(P<0.05)$ between rice cultivars at the same leaf stage were indicated by different lowercases, and the significant differences for total values of $0-2.0 \mathrm{~mm}$ diameter were indicated by different uppercases at the end of the bars, according to Tukey's honestly test.
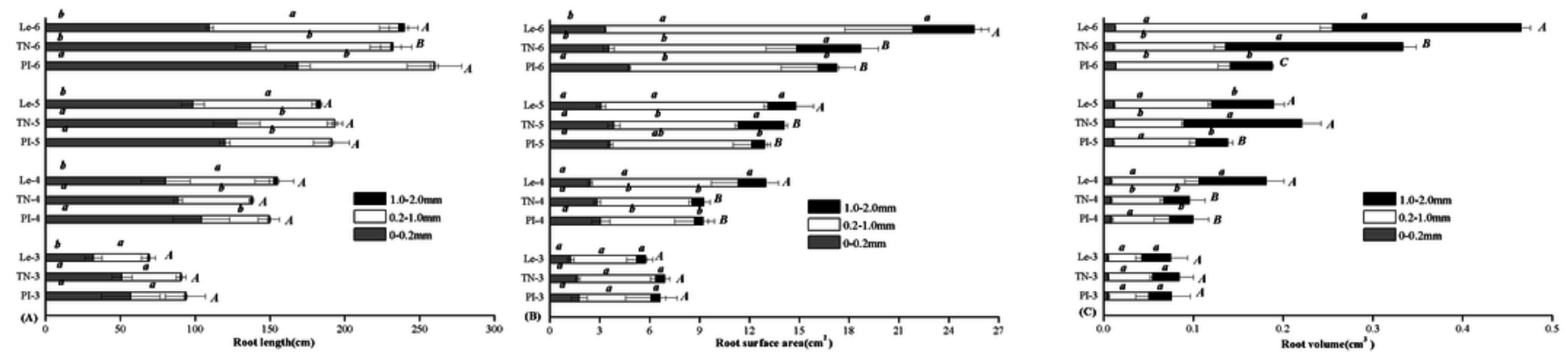


\section{Figure 2}

Fig.2 Root tip number and root biomass (mg plant-1) of the three rice cultivars (PI and TN, allelopathic cultivars PI312777 and Taichung Native1. Le, non-allelopathic cultivar Lemont) at 3-6 leaf stages.

Significant differences $(P<0.05)$ between rice cultivars at the same leaf stage were indicated by different lowercases, according to Tukey's honestly test.

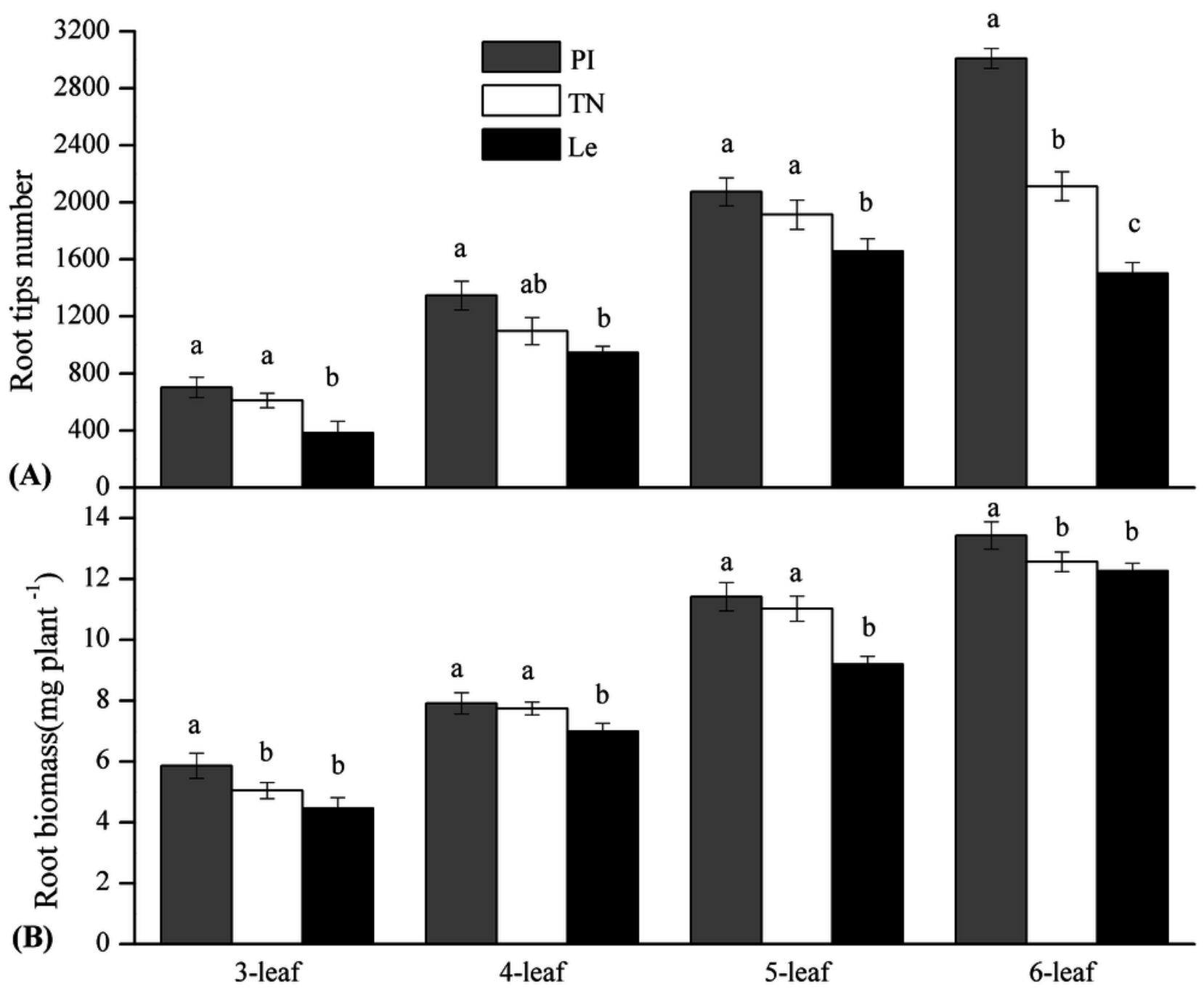




\section{Figure 3}

Fig. 3 The \% inhibition of the root exudates of the three rice cultivars (PI and TN, allelopathic cultivars PI312777 and Taichung Native1. Le, non-allelopathic cultivar Lemont) at 3-6 leaf stages.

Significant differences $(P<0.05)$ between rice cultivars at the same leaf stage were indicated by different lowercases, according to Tukey's honestly test.

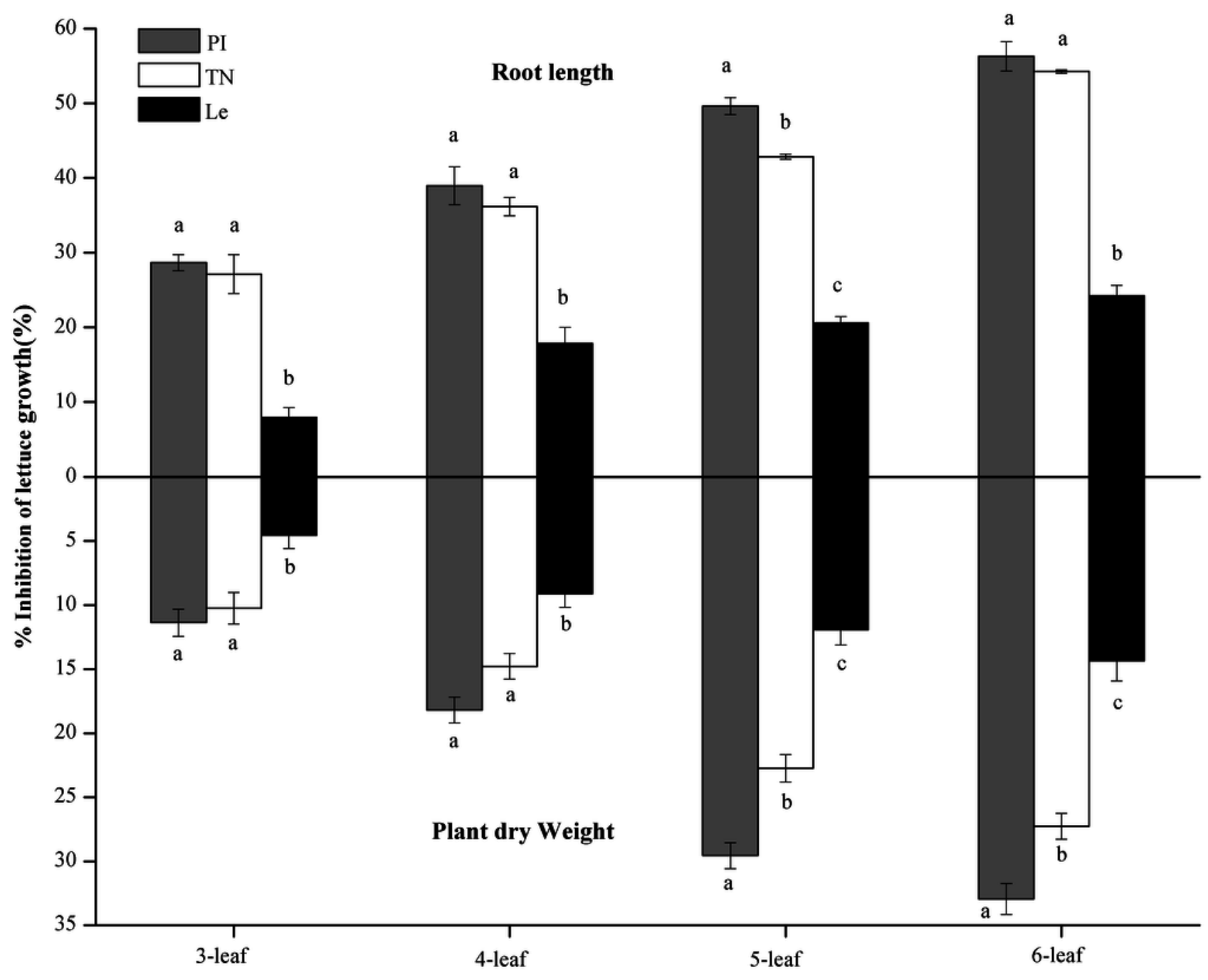


Figure 4

Total contents of eight phenolic acids in rice root-exudates at 3-6-leaf stage.

Significant differences $(P<0.05)$ between rice species at the same leaf stage were indicated by different lowercases according to Tukey's honestly test. PI and TN, allelopathic cultivars PI312777 and Taichung Native1. Le, non-allelopathic cultivar Lemont.

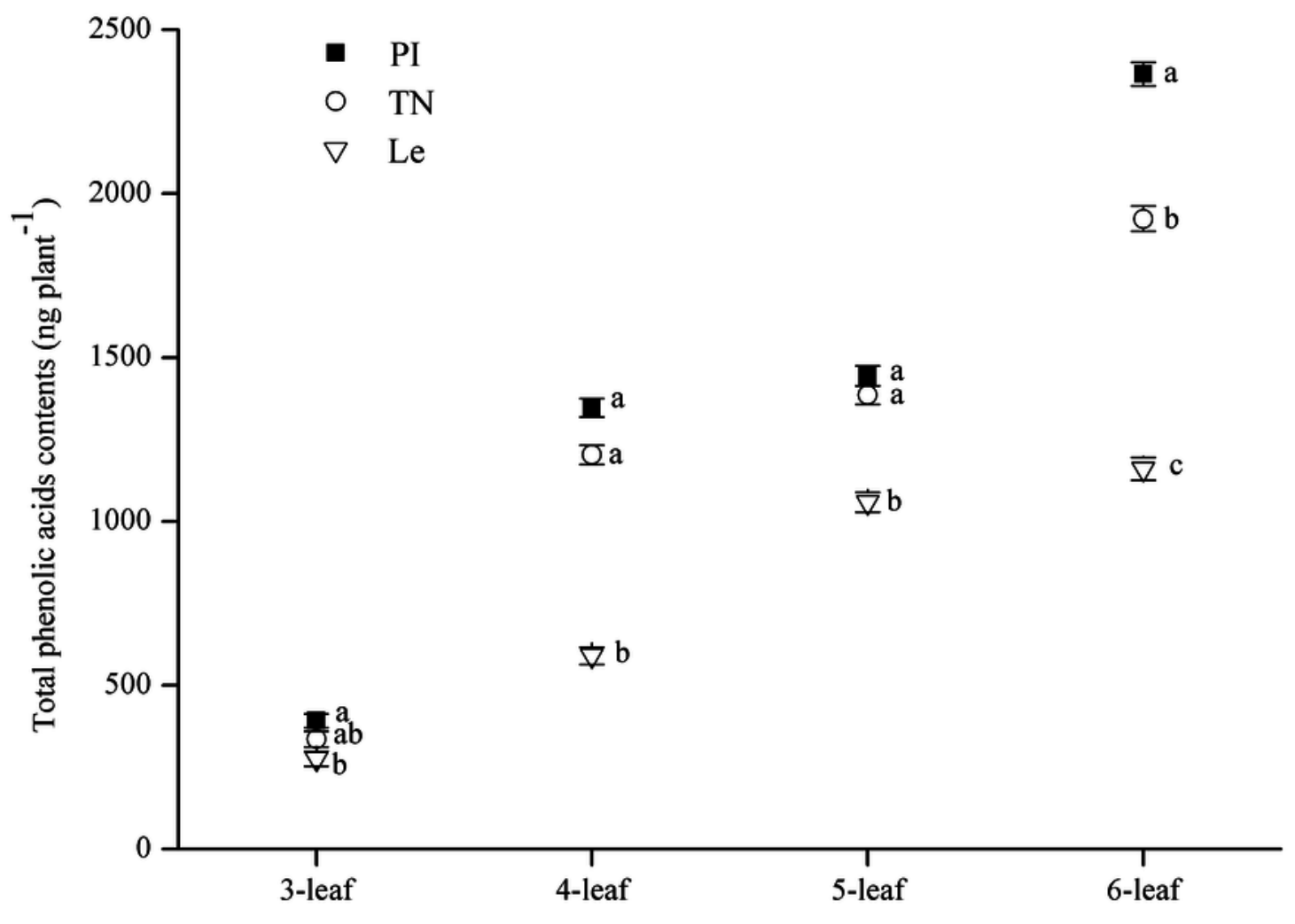




\section{Table $\mathbf{1}$ (on next page)}

Table1 The statistical significance of the effects of leaf-stage and cultivars on fine-root traits, total phenolic acid contents, inhibition on root length and plant dry weight of lettuce. 
1 Table1 The statistical significance of the effects of leaf-stage and cultivars on fine-root traits, total phenolic acid 2 contents, inhibition on root length and plant dry weight of lettuce.

\begin{tabular}{lllll}
\hline Factor & Dependent variable & $\mathrm{df}$ & $\mathrm{F}$ & P value \\
\hline Leaf stage & root length $(0-0.2 \mathrm{~mm})$ & 7 & 114.670 & $0.001^{* * *}$ \\
& root length $(0.2-2.0 \mathrm{~mm})$ & 7 & 10.996 & $0.001^{* * *}$ \\
& root surface area & 7 & 14.815 & $0.001^{* * *}$ \\
& root volume & 7 & 12.646 & $0.011^{*}$ \\
& root tips number & 7 & 1088.983 & $0.002^{* *}$ \\
& root biomass & 7 & 59.672 & $0.000^{* * *}$ \\
& total phenolic acid content & 7 & 11.562 & $0.002^{* *}$ \\
& inhibition on root length & 7 & 17.104 & $0.001^{* * *}$ \\
& inhibition on dry weight & 7 & 7.487 & $0.002^{* *}$ \\
Cultivar & root length $(0-0.2 \mathrm{~mm})$ & 2 & 18.534 & $0.014^{*}$ \\
& root length $(0.2-2.0 \mathrm{~mm})$ & 2 & 1.659 & $0.048^{*}$ \\
& root surface area & 2 & 1.013 & 0.134 \\
& root volume & 2 & 1.644 & 0.116 \\
& root tips number & 2 & 135.944 & $0.040^{*}$ \\
& root biomass & 2 & 5.410 & $0.005^{* *}$ \\
& total phenolic acid content & 2 & 3.388 & $0.028^{*}$ \\
& inhibition on root length & 2 & 52.911 & $0.001^{* * *}$ \\
& inhibition on dry weight & 2 & 9.972 & $0.002^{* *}$ \\
\hline
\end{tabular}

3 The multivariate analysis with General Linear Model were used (Fixed Factors: leaf stage, cultivar). *, $0.01<\mathrm{P}<0.05$;

$4 \quad * *, 0.001<\mathrm{P}<0.01 ; * * *, \mathrm{P}<0.001$.

5

6 


\section{Table 2 (on next page)}

Table 2. The contents of eight phenolic acids in rice root-exudates at 3-6-leaf stage (ng plant $^{-1}$ ) 
1 Table 2. The contents of eight phenolic acids in rice root-exudates at 3-6-leaf stage (ng plant $\left.{ }^{-1}\right)$

\begin{tabular}{|c|c|c|c|c|c|}
\hline Phenolic acid & $\begin{array}{c}\text { cultiva } \\
\text { rs }\end{array}$ & 3-leaf & 4-leaf & 5-leaf & 6-leaf \\
\hline \multirow[t]{3}{*}{ Protocatechuic acid } & PI & $10.58 \pm 0.86$ & $30.49 \pm 5.45$ & $14.62 \pm 1.13$ & $26.82 \pm 2.40$ \\
\hline & $\mathrm{TN}$ & $9.36 \pm 0.36$ & $25.85 \pm 1.59$ & $14.33 \pm 1.25$ & $24.09 \pm 2.52$ \\
\hline & Le & $11.63 \pm 0.52$ & $22.37 \pm 1.32$ & $26.74 \pm 1.24$ & ND \\
\hline \multirow{3}{*}{$\begin{array}{l}p \text {-Hydroxybenzoic } \\
\text { acid }\end{array}$} & PI & $41.43 \pm 1.12$ & $674.65 \pm 9.89$ & $49.46 \pm 3.24$ & $66.56 \pm 2.84$ \\
\hline & $\mathrm{TN}$ & $36.4 \pm 2.86$ & $566.4 \pm 5.26$ & $38.4 \pm 2.31$ & $68.55 \pm 3.01$ \\
\hline & Le & $52.43 \pm 1.14$ & $71.23 \pm 3.09$ & $17.21 \pm 1.22$ & $28.77 \pm 1.93$ \\
\hline \multirow[t]{3}{*}{ Vanillic acid } & PI & $15.74 \pm 0.99$ & $64.14 \pm 6.26$ & $43.84 \pm 6.67$ & $78.37 \pm 4.62$ \\
\hline & $\mathrm{TN}$ & $14.54 \pm 0.82$ & $59.39 \pm 4.37$ & $39.79 \pm 3.14$ & $74.14 \pm 4.84$ \\
\hline & Le & $16.14 \pm 1.53$ & $12.47 \pm 3.25$ & $13.18 \pm 2.29$ & $10.99 \pm 1.68$ \\
\hline \multirow[t]{3}{*}{ Syringic acid } & PI & $59.65 \pm 3.28$ & $43.06 \pm 2.46$ & $111.09 \pm 5.34$ & $282.73 \pm 7.96$ \\
\hline & $\mathrm{TN}$ & $56.66 \pm 3.76$ & $36.87 \pm 3.17$ & $109.38 \pm 6.29$ & $315.89 \pm 7.15$ \\
\hline & Le & $52.66 \pm 1.46$ & $174.05 \pm 6.24$ & $102.95 \pm 6.21$ & $95.42 \pm 2.36$ \\
\hline \multirow[t]{3}{*}{$p$-Coumaric acid } & PI & ND & ND & ND & ND \\
\hline & $\mathrm{TN}$ & $9.45 \pm 0.21$ & $16.37 \pm 0.75$ & $13.41 \pm 0.25$ & $48.54 \pm 1.68$ \\
\hline & Le & ND & ND & ND & ND \\
\hline \multirow[t]{3}{*}{ Ferulic acid } & PI & $9.71 \pm 0.11$ & $19.48 \pm 1.21$ & $14.67 \pm 1.08$ & $53.74 \pm 3.12$ \\
\hline & $\mathrm{TN}$ & ND & ND & ND & ND \\
\hline & Le & ND & ND & ND & $23.87 \pm 1.18$ \\
\hline \multirow[t]{3}{*}{ Salicylic acid } & PI & $252.54 \pm 7.12$ & $499.58 \pm 8.02$ & $1176.52 \pm 11.89$ & $1818.59 \pm 15.14$ \\
\hline & $\mathrm{TN}$ & $207.23 \pm 7.36$ & $483.55 \pm 6.93$ & $1138.91 \pm 12.42$ & $1362.09 \pm 10.22$ \\
\hline & Le & $140.99 \pm 4.37$ & $303.08 \pm 8.14$ & $888.29 \pm 19.51$ & $996.66 \pm 9.78$ \\
\hline \multirow[t]{3}{*}{ Cinnamic acid } & PI & $1.90 \pm 0.12$ & $15.10 \pm 0.31$ & $33.59 \pm 1.78$ & $37.91 \pm 2.13$ \\
\hline & $\mathrm{TN}$ & $1.54 \pm 0.14$ & $14.44 \pm 0.93$ & $31.56 \pm 2.64$ & $30.06 \pm 2.78$ \\
\hline & Le & $1.37 \pm 0.38$ & $6.79 \pm 0.59$ & $10.12 \pm 2.09$ & $4.43 \pm 0.26$ \\
\hline
\end{tabular}

2 Means \pm standard error (SE) from three replications for each determination is shown. 'ND'means compounds not

3 detected in the analysis. PI and TN, allelopathic cultivars PI312777 and Taichung Native1. Le, non-allelopathic 4 cultivar Lemont. 


\section{Table 3(on next page)}

Table 3. Correlation coefficients $(r)$ among total phenolic acids contents of rice rootexudates, rice allelopathic potential andfine- root traits of three rice cultivars. 
Table 3. Correlation coefficients $(r)$ among total phenolic acids contents of rice root-exudates, rice allelopathic potential andfine- root traits of three rice cultivars

\begin{tabular}{|c|c|c|c|c|c|c|c|c|}
\hline & & \multicolumn{2}{|l|}{ Plant } & \multicolumn{5}{|c|}{ Root morphological trait } \\
\hline & & RAP & PAC & $\mathrm{RL}(1)$ & $\mathrm{RL}(2)$ & RTN & RSA & RV \\
\hline \multirow[t]{2}{*}{ Plant } & RAP & 1 & & & & & & \\
\hline & PAC & $0.914 * * *$ & 1 & & & & & \\
\hline \multirow[t]{5}{*}{ Root morphological trait } & $\mathrm{RL}(1)$ & $0.906^{* * *}$ & $0.958 * * *$ & / & & & & \\
\hline & $\mathrm{RL}(2)$ & 0.428 & 0.477 & 0.568 & 1 & & & \\
\hline & RTN & $0.921^{* * *}$ & $0.937 * * *$ & $0.972 * * *$ & 0.437 & / & & \\
\hline & RSA & 0.451 & 0.406 & 0.599 & $0.991 * * *$ & 0.447 & / & \\
\hline & $\mathrm{RV}$ & 0.249 & 0.407 & 0.496 & $0.953 * * *$ & 0.429 & $0.962 * * *$ & / \\
\hline Root proliferative trait & $\mathrm{RB}$ & $0.843 * *$ & $0.895^{* *}$ & $0.946 * * *$ & $0.825 * *$ & $0.928 * * *$ & $0.848 * *$ & $0.698^{*}$ \\
\hline
\end{tabular}

3 RAP- rice allelopathic potential(\% inhibition on plant dry weight of lettuce), PAC- total phenolic acids contents of rice root-exudates, RL(1)- root length at 0-

$40.2 \mathrm{~mm}, \mathrm{RTN}$ - root tips number, $\mathrm{RL}(2)$ - root length at $0.2-2.0 \mathrm{~mm}$, RSA- root surface area, RV-root volume, RB- root biomass. ${ }^{*}, 0.01<\mathrm{P}<0.05$; ${ }^{* *}, 0.001<\mathrm{P}<0.01$; $5 \quad * * *, \mathrm{P}<0.001$ 